This is a self-archived version of an original article. This version may differ from the original in pagination and typographic details.

Author(s): Robazza, Claudio; Ruiz, Montse C.

Title: Emotional Self-Regulation in Sport and Performance

Year: 2018

Version: Accepted version (Final draft)

Copyright: @ Oxford University Press, 2018.

Rights: In Copyright

Rights url: http://rightsstatements.org/page/InC/1.0/?language=en

Please cite the original version:

Robazza, C., \& Ruiz, M. C. (2018). Emotional Self-Regulation in Sport and Performance. In Oxford Research Encyclopedia of Psychology. Oxford University Press.

https://doi.org/10.1093/acrefore/9780190236557.013.154 
Article to appear in the Oxford Research Encyclopedia of Psychology.

\title{
Emotional Self-regulation in Sport and Performance
}

\author{
Claudio Robazza ${ }^{1}$ and Montse C. Ruiz ${ }^{2}$ \\ ${ }^{1}$ BIND-Behavioral Imaging and Neural Dynamics Center, Department of Medicine and Aging \\ Sciences, "G. d'Annunzio" University of Chieti-Pescara, Chieti, Italy \\ ${ }^{2}$ Faculty of Sport and Health Sciences, University of Jyväskylä, Jyväskylä, Finland
}

Emotions are multifaceted subjective feelings that reflect expected, current, or past interactions with the environment. They involve sets of interrelated psychological processes, encompassing affective, cognitive, motivational, physiological, and expressive or behavioral components. Emotions play a fundamental role in human adaptation and performance by improving sensory intake, detection of relevant stimuli, readiness for behavioral responses, decision-making, memory, and interpersonal interactions. These beneficial effects enhance human health and performance in any endeavor, including sport, work, and the arts. However, emotions can also be maladaptive. Their beneficial or maladaptive effects depend on their content, time of occurrence, and intensity level. Emotional self-regulation refers to the processes by which individuals modify the type, quality, time course, and intensity of their emotions. Individuals attempt to regulate their emotions to attain beneficial effects, to deal with unfavorable circumstances, or both. Emotional self-regulation occurs when persons monitor the emotions they are experiencing and try to modify or maintain them. It can be automatic or effortful, conscious or unconscious. The process model of emotion regulation provides a framework for the classification of antecedent- and response-focused regulation processes. These processes are categorized according to the point at which they have their primary impact in the emotion generative process: situation selection (e.g., confrontation and avoidance), situation modification (e.g., direct situation modification, support-seeking, and conflict resolution), attentional deployment (e.g., distraction, concentration, and mindfulness), cognitive change (e.g., self-efficacy appraisals, challenge/threat appraisals, positive reappraisal, and acceptance), and response modulation (e.g., regulation of experience, arousal regulation, and expressive suppression). In addition to the process model of emotion regulation, other prominent approaches provide useful insights to the study of adaptation and self-regulation for performance enhancement. These include the strength model of selfcontrol, the dual-process theories, the biopsychosocial model, the attentional control theory, and the individual zones of optimal functioning model. Based on the latter model, emotioncentered and action-centered interrelated strategies have been proposed for self-regulation in sport. Within this framework, performers identify, regulate, and optimize their functional and dysfunctional emotions and their most relevant components of functional performance patterns.

Keywords: emotion, self-regulation, process model, dual-process theories, attentional control theory, biopsychosocial model, individual zones of optimal functioning model, multi-action plan 


\section{Emotional Self-regulation in Sport and Performance}

Emotional experiences are ubiquitous to human functioning. In sport and other performance achievement domains, such as dance, music, military, surgery, aviation, and medicine, emotions play an important role in performers' lives having short-term and long-term consequences to their functioning by influencing effort, attention, decision-making, memory, behavioral responses, and interpersonal interactions (Blascovich \& Tomaka, 1996; Hays, 2017; Jones, 2012). Functional emotions result in an optimal adaptation and response to specific situational demands, while dysfunctional emotions reflect a lack of resources or inappropriate amount of energy being deployed (Hanin, 2000, 2007). The functional impact of emotional experiences on performance depends on their content, time and frequency of occurrence, intensity level, cognitive appraisal, and ability to self-regulate. In particular, a performer's ability to regulate their emotional experiences is assumed to be key to their success (Lane, Beedie, Jones, Uphill, \& Devonport, 2012). Thus, understanding the processes underlying the ways in which individuals manage their emotional responses is paramount. Paradoxically, emotion regulation in sport and other achievement contexts has received scarce research attention relative to other sub-disciplines of psychology.

This article first provides a description of existing terminology around the concept of emotion self-regulation and related affective phenomena. The second section outlines a framework for the classification of antecedents and consequences of emotion self-regulation processes. The third section presents the theoretical underpinnings of a sport-specific approach applied to the regulation of emotion and performance-related states. The final part describes a model proposed for emotion- and action-centered self-regulation strategies in the optimization of athletic performance.

\section{Conceptualization of Emotional Phenomena and Emotion Self-Regulation}


The understanding of how emotional experiences are manifested, and the specific meaning, causes, and consequences, has important implications for emotion regulation and the use of different regulation strategies. An accurate and detailed description of the object of selfregulation is needed from both conceptual and applied perspectives. Thus, the following section starts by presenting challenges in the conceptualization of the main affective constructs. A definition of emotion self-regulation and comparison with related constructs is presented next.

\section{Emotions and Affective Phenomena}

The emotion literature has been characterized by conceptual confusion. Although there is an intuitive understanding of what emotions are, the definition of emotion remains ambiguous (Vallerand \& Blanchard, 2000). Terminology used in the affective domain, such as affect, emotion, or mood, has been often used interchangeably. Most academics, however, agree that such constructs represent distinct phenomena. Affect is regarded as a superordinate category of phenomena experienced by an individual including feelings, emotions, and moods. Generally used to refer to one's desires and whether they are being met, affect is viewed as information about the value of "whatever comes to mind" (e.g., Clore \& Huntsinger, 2007). Affect is usually conceptualized using global dimensions such as hedonic tone (i.e., pleasure/displeasure) and activation (i.e., tension/relaxation; Russell, 2003). A different perspective considers emotions as discrete categories emphasizing the qualitative content and the role of cognitive appraisals (e.g., Lazarus, 2000). According to this perspective, emotions are triggered by the person's appraisal of the significance of their interactions with the environment, typically in terms of personal harms or benefits. Such interactions result in specific emotions, which are characterized by distinct relational meaning or core relational themes. This approach, thus, considers causal cognitive, motivational, relational variables, and processes involved in initiating and sustaining an emotion (Lazarus, 2000). Several 
discrete categories have been identified, some of which are positively-toned emotions (e.g., happiness, pride, relief) and others negatively-toned emotions (e.g., anger, anxiety, shame). Emotion theorists, however, do not agree on a particular number of emotions or what constitutes the specific emotions (Scarantino, 2015).

Emotions have been distinguished from moods based on the cause or triggering event, duration, intensity, and action tendencies (Beedie, Terry, \& Lane, 2005; Ekkekakis, 2012; Shuman \& Scherer, 2015). Theorists agree that emotions have an identifiable cause, are short term and more intense, have specific tendencies for action and a differentiated subjective feeling, while moods do not have an object, last longer in time, have broader approachavoidance tendencies, and are more diffuse. Several specific measures have been developed to assess affective related phenomena (see Ekkekakis, 2012, for a review).

A different approach to overcome such conceptual confusion, which would include the phenomenology of emotions, focuses on the subjective emotional experience and the description of its defining characteristics (Hanin, 2000, 2007). Emotional experiences are viewed as composite and multicomponent constructs reflecting person environment relationships. In particular, emotional experiences have been conceptualized as indivisible components of total human functioning reflecting the nature of expected, current, or past interactions with the environment (Hanin, 2000). Subjective feelings or experiences, physiological responses, and behavioral expressions have been typically regarded as the main components of emotions. The subjective experience is related to one's evaluation of the significance of a specific transaction between the person and the environment. Physiological or bodily responses usually include changes in heart rate, blood pressure, and visceral functioning, and further reactions in the autonomic nervous system. Behavioral expressions triggered by emotions are usually associated with approach-avoidance tendencies (Elliot, Eder, \& Harmon-Jones, 2013; see Shuman \& Scherer, 2015, for a review). These emotion 
components, which originate from distinct methodological approaches (e.g., self-reports, physiological measures, behavioral observation), do not seem to provide comprehensive information about emotional experiences. Some researchers have highlighted the importance of cognitive appraisals such as evaluations in terms of challenge or threat (Blascovich, 2008; Blascovich \& Tomaka, 1996), or a set of interrelated processes encompassing affective, cognitive, motivational, physiological, expressive or behavioral, and social components (see also further description of the individual zones of optimal functioning model).

\section{What Is Emotion Regulation?}

Emotions are associated with specific subjective experiences and tendencies for action. People, however, may choose not to act upon such tendencies suppressing their emotions. Emotion regulation refers to the process by which individuals modify the type, quality, time course, and intensity of their emotions (Peña-Sarrionandia, Mikolajczak, \& Gross, 2015). In line with existing distinctions among affective phenomena, emotion regulation literature includes different terminology referring to mood regulation or affect regulation, depending on the target of regulation (Niven, Totterdell, Stride, \& Holman, 2011). Researchers have distinguished between two types of emotion regulation: the regulation of one's own emotions, namely intrinsic or intrapersonal emotion regulation, and the regulation of other's emotions, namely extrinsic or interpersonal emotion regulation (Campos, Walle, Dahl, \& Main, 2011; Friesen et al., 2013). The first type of regulation, also called emotion self-regulation, has received most research attention and is the focus of this article.

Emotion regulation is part of the broader construct of self-regulation, which generally describes the efforts made to manage one's inner states such as thoughts, feelings, actions, or interpersonal processes that are deliberately planned and adapted to the achievement of personal goals (Baumeister, Vohs, \& Tice, 2007; Zimmerman, 2006). A key construct related to emotion regulation, which sometimes has been used interchangeably, is self-control. Self- 
control refers to the deliberate or conscious efforts to override dominant behaviors or response tendencies in order to achieve a specific goal (Baumeister et al., 2007). For instance, in a competition an athlete may control his or her urge to shout at an umpire who has made a poor call affecting the results, and thus, avoid possible negative consequences of such behavior. In the strength model of self-control, the person's capacity to exert self-control is viewed as limited (Baumeister et al., 2007; Muraven \& Baumeister, 2000). According to this model, voluntary acts of self-control lead to a temporary reduction of self-regulatory resources, an effect termed "ego depletion." Such effect is thought to impair the ability for further self-regulation until the resources are replenished. Empirical evidence suggests that some types of emotion self-regulation strategies are more resource diminishing than others. For instance, Sheppes and Meiran (2008) found that providing participants instructions to reappraise (change the emotional meaning) during a sadness-inducing film consumed higher resources than distraction, demonstrated in poorer subsequent performance on the Stroop test. Another construct closely related to emotional self-regulation is coping, although the literatures on coping and emotion regulation have tended to be separate and disconnected. Emotion self-regulation refers to automatic or deliberate actions to initiate, maintain, or change one or more components of an emotional response or the situation in which emotional experiences take place (Gross, 2015; Peña-Sarrionandia et al., 2015; Ray, McRae, Ochsner, \& Gross, 2010). Thus, three possible ways to regulate emotions have been distinguished. Emotion regulation can be aimed at decreasing the intensity of an emotional response (downregulation), at increasing the intensity of an emotional response (up-regulation), or at keeping the intensity of an emotional response stable over time (maintenance). Coping, however, has been conceptualized as the cognitive and behavioral efforts to manage specific demands that are appraised as stressful, in that they tax or exceed the resources of the person (Lazarus \& Folkman, 1984). In coping, which occurs in response to stressful situations, the main focus is 
decreasing unpleasant emotional experiences, while emotion regulation may occur in nonstressful situations, involving the process of changing or maintaining pleasant emotions. Drawing from the work of Lazarus and Folkman (1984), two general types of coping processes have been distinguished. The first, termed problem-focused coping, is aimed at taking actions with the purpose of targeting the causes of stress or practical ways to directly reduce the stress. The second, termed emotion-focused coping, involves the reduction or management of the emotional distress associated with the situation. Thus, coping is considered a special case of emotion regulation under stress (Skinner \& Zimmer-Gembeck, 2007) or a form of down-regulation.

Researchers have shown that emotion regulation may involve attaining two main goals - hedonic and instrumental (Tamir, 2009). Hedonic emotion regulation serves the need aimed at promoting pleasure and preventing pain, and consists of up-regulation of pleasant emotions and down-regulation of unpleasant emotions. For example, an athlete may listen to music to calm down before a race. In some cases, however, individuals may choose to upregulate or down-regulate either pleasant or unpleasant emotions in order achieve a particular goal. In the sport context in particular, it is reasonable that athletes are motivated to experience unpleasant emotions such as anger or anxiety in the short term when they believe that this will facilitate performance.

The following section presents a framework involving antecedent- and responsefocused emotion regulation strategies.

\section{The Process Model of Emotion Regulation}

The process model of emotion regulation (Gross, 1998) provides a conceptual organization for classifying emotion regulation strategies. The model distinguishes between the processes occurring before and after emotions are experienced, based on the evidence that people use different strategies at different points in the emotion generative process. 
Accordingly, five families of emotion regulation strategies are identified following the occurrence of a potentially emotion-eliciting situation (see upper part of Figure 1). Arrows in Figure 1 indicate time changes on how a specific situation is selected, modified, attended to, appraised, and results in a set of emotional responses. The curved feedback arrow represents the dynamic aspect of emotion and emotion regulation that extends beyond a single episode. Four families of regulation strategies are antecedent-focused and involve efforts to control or modify emotions before their appearance. The last family of regulation strategies is responsefocused and is related to attempts to change the subjective, expressive, or physiological aspects of emotions when the experience is already happening. Compared to antecedentfocused regulation, response-focused regulation — in particular suppression - may require greater resources (i.e., more cognitive effort) to monitor and regulate emotion-expressive behavior (Richards \& Gross, 2000). Three common (core) features of emotion regulation are the activation of a regulatory goal (i.e., what people try to accomplish), the emotion regulation strategy (i.e., the particular processes to achieve the goal), and the outcome (i.e., the consequences of trying to achieve an emotion regulation goal using a particular strategy; Gross, 2014). Emotion regulation goals may involve down-regulating unpleasant emotions (e.g., diminishing the intensity or duration of anxiety or anger) or up-regulating pleasant emotions (e.g., increasing the magnitude or duration of happiness and excitement). Individuals may also seek to up-regulate unpleasant emotions or down-regulate pleasant emotions for instrumental reasons. For example, in collision sports, such as rugby, athletes often try to enhance their anger feelings and reduce complacency to be better prepared to face aggressive opponents (Robazza \& Bortoli, 2007).

\section{[Insert Figure 1]}

To attain a regulatory goal, individuals consciously or unconsciously regulate their emotions by modifying the trajectory of one component or more components of the emotional 
responses. "Emotion regulation can thus serve to influence the type (i.e., which emotion one has), intensity (i.e., how intense the emotion is), time course (i.e., when the emotion starts and how long it lasts), and quality (i.e., how the emotion is experienced or expressed) of the emotion" (Peña-Sarrionandia et al., 2015, p. 1). This regulation may be intrapersonal, when referred to one's own emotions, or interpersonal, if referred to someone else's emotions. It may be automatic (unconscious) or effortful (conscious), and occurring when an individual activates the goal to influence the emotion-generative process (Gross, Sheppes, \& Urry, 2011).

\section{Situation Selection}

Situation selection refers to the process of choosing or avoiding certain activities, situations, or contexts depending on their expected emotional impact. Situation selection is placed at the very start of the emotion process, and thus shapes the whole emotion trajectory. The individual goal is to make more likely the occurrence of a desirable emotional state. Adaptive situation selection involves knowing personal needs, anticipating the emotions that will be experienced, and considering these emotions when selecting the situation.

Confrontation and avoidance are two situation selection strategies. Short- and long-term costs and benefits should be evaluated before making a choice between the two strategies.

Confrontation involves deciding to face a situation notwithstanding the unpleasant emotions that may arise from this choice. An exhausted soccer player, for example, may take the responsibility to execute a penalty kick in a crucial phase of the match, and try to downregulate unpleasant feelings of anxiety and worry while facing this challenge. On the other hand, avoidance may be a better choice when a situation may bring more detrimental than beneficial effects, or future benefits are not likely to occur. The player may opt to transfer the charge of the penalty kick to a rested teammate. However, avoidance is likely to become dysfunctional when it is difficult to escape the situation or justify disengagement. This might 
happen if the soccer player refuses to take responsibilities without justifiable motives. In general, confrontation is usually effective in improving long-term happiness and mental health, in spite of the unpleasant emotions produced in the short-term (Aldao, NolenHoeksema, \& Schweizer, 2010). In contrast, avoidance is frequently associated with poor indicators of long-term well-being and health.

\section{Situation Modification}

Situation modification involves strategies aimed to alter the features of a situation to change its emotional effect. It is sometimes difficult to clearly distinguish between situation selection and situation modification. Yet, situation selection is related to changing aspects of one's self with respect to the environment, whereas situation modification refers to attempts to modify external aspects of the environment. Situation modification strategies encompass, among other things, direct situation modification, support-seeking, and conflict resolution. Direct situation modification, also known as problem-focused coping in the stress literature (Lazarus \& Folkman, 1984), involves practical actions to directly change the situation. Devising and executing tactical schemes in team sports or identifying the best climbing route in a mountaineering expedition are examples of this type of strategy. Seeking assistance from others (i.e., support-seeking) and resolving conflicts that often arise in social contexts are also fundamental strategies in performance domains such as those exemplified. However, despite their early impact on the emotion generative process, neither situation selection nor situation modification can prevent or change every situation that elicits emotions. Additional strategies are then necessary to shape the trajectory of the unfolding emotional experience.

\section{Attentional Deployment}

Attentional deployment occurs after situation modification. It refers to how individuals direct their attention to increase or decrease the occurrence of specific emotions and modify their impact. Two forms of attentional deployment are distraction and 
concentration. Distracting attention away from the emotional cues of a situation can be used in combination to directing attention on non-emotional aspects. Focusing attention on muscle relaxation, breathing, imagery, self-talk, and decision-making processes, and mimicking actions in a preperformance routine have been associated with adaptive emotional and performance outcomes in sport (Cotterill, 2010; Mesagno, Hill, \& Larkin, 2015). Concentration on feelings refers to attention directed to causes, thoughts, sensations, and consequences. Although found to increase the duration and magnitude of unpleasant emotions (Bushman, 2002), focusing on one's feelings may be functional in some circumstances. Drawing on Maxwell's (2004) findings showing that anger rumination was a significant predictor of aggression, Uphill, McCarthy, and Jones (2009) suggested that focusing on thoughts and feelings associated with anger may be desirable for instrumental purposes, for example in combat sports such as wrestling. This is consistent with the view that individuals are not only motivated by short-term hedonic goals (i.e., feel pleasure), but also by instrumental goals (i.e., to perform certain behaviors) despite hedonic costs (Tamir, Mitchell, \& Gross, 2008).

\section{Cognitive Change}

Cognitive change involves modifying the meaning or significance of a situation in order to change one's feelings. Three forms of cognitive change are self-efficacy appraisal, challenge and threat appraisal, and positive reappraisal. Self-efficacy appraisal is the individual's perceived ability to deal with the situation. In performance contexts self-efficacy appraisal is regarded as an important variable influencing a performer's choice of goals and effectiveness to face an event (Bandura, 1997; Feltz, Short, \& Sullivan, 2008). Self-efficacy beliefs are based mainly on past performance accomplishments, which include past experiences implementing self-regulation or mental preparation strategies, such as setting realistic goals, using motivational imagery and positive self-talk, relaxation, and distraction 
(Brown \& Fletcher, 2017; Munroe-Chandler \& Guerrero, 2017; Scorniaenchi \& Feltz, 2010; Uphill et al., 2009; Van Raalte \& Vincent, 2017; Zakrajsek \& Blanton, 2017). Repeated success implementing these strategies increases efficacy beliefs, whereas ineffective implementation decreases self-efficacy.

Challenge and threat appraisal relates to one's evaluation of perceived benefits and harms in demanding person-environment transactions (Lazarus \& Folkman, 1984). According to the biopsychosocial model (Blascovich, 2008; Blascovich \& Tomaka, 1996), challenge and threat are motivational states that include cognitive, affective, and physiological components reflecting how an individual appraises and engages in a personally meaningful situation. Before being involved in a motivated task, individuals evaluate both situational demands and personal resources. A challenge state is experienced when an individual perceives having sufficient resources to manage the demands of the task. In contrast, a threat state is experienced when the person perceives lacking resources to face a demanding task. Drawing on the biopsychosocial model, Jones, Meijen, McCarthy, and Sheffield (2009) proposed the theory of challenge and threat states in athletes, and posited distinct patterns of neuroendocrine and cardiovascular activity in response to a challenge or threat state. Accordingly, a challenge state is characterized by high levels of self-efficacy and perceived control, approach goals, either pleasant or unpleasant emotions perceived as helpful for performance, increases in epinephrine and cardiac activity, and reduced total peripheral vascular resistance. On the other hand, a threat state is typified by unpleasant emotions perceived as harmful, increases in cortisol, and smaller increases in cardiac activity associated with stable or enhanced peripheral vascular resistance. Vine and colleagues found that challenge and threat evaluations predicted performance in a pressurized environment requiring accurate execution of a novel motor task (i.e., laparoscopic surgery; Vine, Freeman, Moore, Chandra-Ramanan, \& Wilson, 2013). Findings support interventions designed to 
encourage individuals to (re)appraise demanding tasks more adaptively (i.e., in terms of challenging instead of threating; McGrath, Moore, Wilson, Freeman, \& Vine, 2011), particularly in pressurized contexts such as sport, military, surgery, aviation, and emergency medicine.

Reappraising a situation as challenging instead of threatening is a form of positive reappraisal. Webb, Miles, and Sheeran (2012) distinguished three other forms of reappraisal regarding emotional response, emotional stimulus, and perspective taking. An emotional response may be interpreted as normally occurring under particular circumstances (e.g., "people usually feel anxious to perform in front of a large audience"), or an emotional stimulus may be appraised as functional (e.g., "I am proud to perform in this context"). Individuals can also adopt a more objective perspective while examining the situation and view circumstances as detached observers.

\section{Response Modulation}

Response-focused regulation strategies occur late in the emotion-generative process and are employed once an emotion has already been elicited. These strategies are intended to modify experiential, physiological (arousal), and/or expressive (behavioral) components of the emotional response. Regulation of experience entails attempts to suppress or, vice versa, focus on thoughts that accompany feelings. It should be noted, however, that attempts to suppress thoughts and emotions, especially under cognitive load, tend to determine a paradoxical, ironic, and counterproductive effect of increasing the return of suppressed thoughts and feelings (Wegner, 1994, 2009). Arousal regulation strategies have a long tradition in sport psychology (Williams, 2010). Athletes use a variety of self-regulatory techniques to adjust their arousal levels to meet the requirements of the task and personal preferences. These include modifying breathing rate and type (i.e., thoracic or abdominal), muscular tension/relaxation, energizing/de-energizing thoughts and mental images, behavioral 
routines, and listening to music (Karageorghis, 2017; Weinberg \& Gould, 2015). Regulation of expressive behavior involves the suppression or amplification of bodily expressions of emotions, including facial, vocal, somatic, and movement displays, which might, in turn, modulate one's emotional experiences (see Quoidbach, Mikolajczak, \& Gross, 2015). Expressive behavior relates to the social sharing of emotions, or interpersonal emotion regulation, a frequently and commonly used response modulation strategy with which individuals influence and regulate the intensity and duration of their own and others' emotional experiences (Rimé, 2009). Athletes, for example, can up-regulate or amplify their emotional expression in order to motivate and enhance the efforts of their teammates or, conversely, down-regulate or suppress emotional manifestations to avoid distracting or overcharging teammates during competition (Friesen et al., 2013). This reinforces the view that emotions and emotion regulation should be considered social phenomena (Tamminen \& Bennett, 2017) that can be examined and understood from an interpersonal perspective.

\section{Mindfulness and the Process Model of Emotion Regulation}

Mindfulness is defined as purposefully allocating sustained attention to thoughts, feelings, bodily sensations, emotional cues, and external events that occur in the present moment in a nonjudgmental manner (i.e., without judging the experience as good/bad or right/wrong; Moore, 2016). A nonjudgmental awareness is a core component of mindfulness, which allows for a healthy experience and expression of emotional content without emotional under- or over-engagement manifested through avoidance/thought suppression or worry/rumination, respectively (Moore, 2016). Mindfulness- and acceptance-based models provide an alternative view for self-regulation of dysfunctional emotions aimed to enhance both well-being and performance (Gardner \& Moore, 2012; Sappington \& Longshore, 2015). Rather than pursuing the control or change of the type, frequency, or duration of one's thoughts, feelings, and physiology, mindfulness- and acceptance-based interventions seek to 
develop a modified relationship with internal experiences in order to view them as normal, unthreatening, and time-limited (Gardner, 2016; Gardner \& Moore, 2007). Individuals do not need to engage in behaviors that seek avoiding or altering such situations, or their cognitive processes. Feelings are regarded in a decentered perspective as transient and objective events of the mind that do not necessarily reflect truth or reality, or need action.

The different perspective that a mindfulness approach offers can substantively contribute to the indications stemming from the process model of emotion regulation (Farb, Anderson, Irving, \& Segal, 2014). Indeed, “while emotion regulation sometimes entails modulating the intensity or frequency of an emotional state, it also involves the highly adaptive capacity to generate, sustain, and tolerate emotions when necessary and appropriate for situational adaptation" (Moore, 2016, p. 31). Figure 1 depicts emotion regulation for performance enhancement in the framework of both mindfulness and the process model.

In the situation exposure stage (corresponding to the situation selection in the process model), the performer experiences, accepts, and tolerates his or her own internal cognitive, emotional, and physiological reactions, making no efforts to reduce feelings or bypass them. Situation acceptance involves nonjudgmental acceptance of, and decentering from, internal experiences. The result is an improved comfort with the emotional experience and reduced need to minimize, avoid, or escape from it (Gardner \& Moore, 2007; Kabat-Zinn, 1990). With a mindful focus, the performer enhances task-relevant attention, and thus effectively responds mentally and physically to task-related demands while experiencing emotion. Cognition acceptance and decentering entail tolerance and acceptance of one's cognitions, considering them as internal events that are naturally occurring, time-limited, and hypotheses not necessarily representing facts or absolute truths. Finally, experience tolerance/acceptance leads to habituation of emotion eliciting stimuli and performance-related experiences. 
The following section outlines the individual zones of optimal functioning (IZOF; Hanin, 2007) model as a theoretical framework specifically for sports with important implications for self-regulation. The section starts by providing a conceptualization of subjective experiences associated with athletic performance. The main principles of the model as applied to emotion regulation are presented next.

\section{Subjective Emotional Experiences}

The IZOF model (Hanin, 2007, 2010) places special emphasis on an accurate description of subjective emotion and emotion-related states (i.e., psychobiosocial states) adopting a holistic perspective. The model distinguishes three types of interrelated emotional experiences. The first are state-like experiences, which are circumstantial manifestations related to how an athlete feels at a certain moment in time. For instance, one athlete may feel relaxed prior to a competition, which denotes a situational state. The second type of experiences or trait-like experiences refer to relatively stable or typical emotional responses in similar situations. Trait-like experiences involve dispositions or how an athlete usually feels, for example a tendency to be anxious prior to competitions. Thirdly, the awareness, attitudes, and preferences that individuals have toward their experiences are called meta-experiences (Nieuwenhuys, Vos, Pijpstra, \& Bakker, 2011). For instance, a performer may feel worried and uncomfortable toward his or her feeling relaxed if this state is appraised as reflecting lack of readiness for the upcoming performance.

Three main characteristics define the structure of state-like experiences, namely form, content, and intensity (Figure 2). Form refers to the way in which emotional experiences are subjectively expressed or manifested in an observable manner. In the IZOF model, emotions are multimodal and can be displayed in eight specific and interrelated psychobiosocial components. Thus, a psychobiosocial state involves affective, cognitive, motivational, volitional, bodily, motor-behavioral, operational, and communicative components (Hanin, 
2010; Ruiz, Hanin, \& Robazza, 2016). This conceptualization implies that regulation is not limited to one component (i.e., affective), but it can be applied to each of the state modalities. For instance, Robazza, Pellizzari, and Hanin (2004) developed a multimodal self-regulation program targeting emotion and bodily symptoms of hockey players and gymnasts, while Middleton, Ruiz, and Robazza (2017) incorporated music in swimmers' preperformance routines for self-regulation of the whole range of psychobiosocial states. Content refers to the type or quality of the experiences. Combining discrete emotion and dimensional affect approaches, the IZOF model distinguishes four categories based on functioning (successfailure) and hedonic tone (pleasure-displeasure). The functionality-hedonic tone interplay leads to functional pleasant, functional unpleasant, dysfunctional unpleasant, and dysfunctional pleasant experiences. Thus, regulation is not only limited to coping with unpleasant experiences. Taking a more comprehensive view, self-regulation can involve down-regulating or up-regulating dysfunctional or functional experiences respectively, or maintaining optimal states notwithstanding their pleasant or unpleasant valence.

\section{[Insert Figure 2]}

Intensity is also a critical defining characteristic for emotion regulation. The IZOF model claims that there is an optimal level of intensity in which athletes may perform up to their potential. Based on the "in-out of the zone" notion, emotions need to be regulated when either below or above optimal intensity levels. The model assumes that both the content and the intensity of emotional states may vary across situations (e.g., practice vs. competition), and across time (e.g., pre-, mid-, and post-event). Thus, for self-regulation it is important to start by identifying the content of emotional states and their optimal and dysfunctional intensity zones. Typically this is done within the context of most and least successful performances. Specific assessment procedures aimed to identify the content and intensity of optimal and dysfunctional states, grounded in the IZOF model, include individualized emotion profiling 
(Hanin, 2000) and psychobiosocial states profiling procedures (Ruiz et al., 2016). These procedures are used to help athletes generate profiles including individually meaningful emotion and emotion-related descriptors associated with optimal and non-optimal performances, and their intensity. Athletes may also rate the functional impact of each of the identified experiences in terms of how helpful or harmful they are for their performance. Beyond idiographic methods, nomothetic questionnaires have also been developed to assess psychobiosocial states (Robazza, Bertollo, Ruiz, \& Bortoli, 2016b; Ruiz, Robazza, Tolvanen, \& Hanin, 2018). The creation of individual profiles is expected to increase one's awareness of functional and dysfunctional psychobiosocial patterns and stimulate the performer to identify and initiate self-regulation strategies (Harmison, 2006; Harmison \& Casto, 2012).

Kamata, Tenenbaum, and Hanin (2002) proposed a probabilistic computational approach, based on logistic regression analysis, as an alternative method to determine the individual zones of optimal/poor functioning of affective states derived from introspective (e.g., pleasure and arousal) or objective data (e.g., heart rate and skin conductance). With this method, reliable idiosyncratic zones of affect intensity were established in athletes from different sports (e.g., Edmonds, Tenenbaum, Mann, Johnson, \& Kamata, 2008; van der Lei \& Tenenbaum, 2012). Following the identification of idiosyncratic zones of pleasure, arousal, heart rate, and skin conductance levels, Edmonds et al. (2008) used biofeedback to train individuals to self-regulate their affective state. After the intervention, findings showed improved performance in a race car simulator task on those participants who underwent treatment conditions designed to maintain individual optimal affect-related performance zones. This line of research and practice provides an interesting avenue for applying biofeedback and neurofeedback self-regulation training within the IZOF framework.

In addition to examining emotional states, the identification of emotional patterns may indicate possible regulation challenges to deal with typical but inadequate emotional 
responses. The identification of meta-experiences can provide information about their appropriateness or whether they may need to be changed. For example, an athlete may approach a sport psychology consultant with the purpose of learning to cope with or reduce feelings of anxiety prior to competition. This may reflect a negative attitude toward anxiety possibly perceived as harmful for performance. However, a further examination of the typical emotional patterns may indicate the existence of intense anxiety prior to successful performance. In this case, it may be recommended that the intervention targets a reflection and re-evaluation of the conditions leading to good and poor performances, which consequently changes knowledge and beliefs about the experience (i.e., the meta-experience) instead of reducing anxiety (Woodcock, Cumming, Duda, \& Sharp, 2012). Thus, metaexperiences play a crucial role in determining the selection, implementation, and effectiveness of self-regulation.

\section{Main Principles and Emotion-Performance Predictions}

The IZOF model holds several principles about the relationship between emotions and performance. The model states that functional and dysfunctional emotions are triggered by the appraisals of the interaction with the environment and the likelihood of achieving relevant goals. Emotion-performance relationships are assumed to be bi-directional, suggesting that pre-event emotions can influence performance (regulatory function), and ongoing performance influences mid-event and post-event emotions (signalling function of emotions). For instance, prior to performance, athletes' appraisals involve the anticipation of gains or losses, which elicit challenge emotions (e.g., feeling hopeful, confident) or threat emotions (e.g., feeling anxious, worried), respectively. Once performance is over, concrete gains or losses trigger emotions that mirror the occurred benefits (e.g., feeling happy, relieved) or harms (e.g., feeling angry, disappointed). 
Emotion-performance relationships are explained based on the individual's availability of resources and their ability to use them effectively in dealing with task demands (Hanin, 2000). Functional effects of emotional states on performance are related to energy mobilization (energizing) and energy utilization (organizing) effects. Conversely, dysfunctional effects of emotions reflect a lack of energy (de-energizing) or misuse of energy (disorganizing). The prediction of performance is based not only on separate effects, but also on the interaction of both functional and dysfunctional pleasant and unpleasant emotions. The highest probability of successful performance is assumed to occur when the athlete experiences high functional and low dysfunctional effects. Thus, emotion regulation should consider both functional and dysfunctional effects of emotional states. Ample empirical evidence supports these principles (Hanin, 2007; see Ruiz, Raglin, \& Hanin, 2017, for a review).

As previously noted, the concept of meta-experience is critical for self-regulation (Nieuwenhuys et al., 2011). Meta-experiences, which usually develop from an evaluation of past performances, provide information of the athletes' awareness of how helpful or harmful for performance their emotions are. They influence the individuals' appraisals of the situation and their choice of regulation strategies. The process of regulation (Figure 2) usually involves three steps: (a) the individuals' awareness of the content and intensity of their functional and dysfunctional psychobiosocial states, (b) the acceptance of their states and functional impact, and (c) the implementation of regulation strategies (Hanin, 2007, 2010).

The IZOF model extends the traditional emotion-focused and problem-focused coping distinction. In the traditional view (Lazarus \& Folkman, 1984) the emotion-focused coping emphasis is on dealing with emotional responses, while problem-focused coping targets the situations and its causes. In the IZOF model, however, regulation targets actions (taskexecution process) and the subjective psychobiosocial experiences accompanying them. 
Emotion-focused coping aims at the maximization of the impact of functional emotional experiences (pleasant and unpleasant) and the minimization of dysfunctional emotional experiences (pleasant and unpleasant). Based on the emotion-performance relationship dynamics, regulation can be reactive when dealing with occurred task-executions and/or emotional experiences, or anticipatory when dealing with task-executions and/or emotional experiences potentially susceptible to regulation.

\section{The Multi-Action Plan (MAP) Model}

The multi-action plan (MAP) model has been developed in sport to account for the multiple performance states athletes experience during training and competition, and to help them consistently achieve and maintain high execution standards and performance outcomes (Bortoli, Bertollo, Hanin, \& Robazza, 2012).

\section{Origins and Underpinnings of the MAP Model}

The main ideas that inspired the MAP construction came from Hanin and Hanina's (2009) identification-control-correction (ICC) program, also meant to optimize execution consistency and performance of elite athletes. Rooted in the IZOF framework (Hanin, 2007), the focus of the ICC program is on action-centered strategies that can be used in conjunction with emotion-centered self-regulation (Hanin, Hanina, Šašek, \& Kobilšek, 2016). A key notion in the ICC program is that regulating emotion content and intensity only does not guarantee the achievement of the expected outcomes. Thus, a combination of action- and emotion-centered self-regulation is expected to be more effective. A further key tenet is that focusing on a few "core" components of the action helps the athlete maintain the movement pattern within a range of functional variability naturally occurring while executing, especially under pressure. Motor tasks are stored in long-term memory as movement sequences in which the core components are intertwined to determine the functionality of action patterns. The mental representation of the action chain of high-level performers is idiosyncratic and, 
therefore, could be different from an "ideal" technical pattern identified, for example, from biomechanical data of elite athletic samples. Like the IZOF-based emotion profiling, (Hanin, 2000, 2007), the ICC program encourages performers to become aware of the idiosyncratic movement patterns underpinning their effective and ineffective task executions, and to identify the functional links among the action components that influence performance. Enhancing the athletes' awareness of their idiosyncratic core components is expected to increase movement control and self-confidence in practice and competition.

Similar to the ICC program, the MAP model combines action- and emotion-centered self-regulation (Robazza, Bertollo, Filho, Hanin, \& Bortoli, 2016a). Central to the MAP is a 2 $\times 2$ notion describing the interplay between performance and action control levels, which complements the $2 \times 2$, performance and emotion hedonic tone (pleasure-displeasure) distinction as conceptualized in the IZOF model (Hanin, 2000, 2007; see previous description of IZOF). These relationships are illustrated in Figure 3. Panel A and Panel B show the four performance states deriving from the interplay between performance and control levels (Panel A), and between performance and hedonic valence levels (Panel B). Type 1 state refers to optimal-automatic performance (i.e., high performance and low control) and functionally pleasant emotional states (i.e., high performance and pleasant hedonic valence). The performer usually experiences a flow-like state, feels in complete control of the situation, exhibits high levels of self-confidence, physical and mental energy, and is able to direct energies toward task execution. Functionally optimal-pleasant emotional states before and during activity are triggered by the appraisal of challenge. The movement is governed by a parallel processing (i.e., action "supervision"), seems autonomous and effortless, and is smooth, consistent, and effective (Csikszentmihalyi, Latter, \& Duranso, 2017; Ericsson, 2003; Harmison, 2006). 
This flow-like, highly self-rewarding psychophysiological state is rare, elusive, and not easy to attain, especially under pressure. High-level achievements, however, can also be reached through a Type 2 state (Figure 3 ) typified by a more conscious attentional focus on the core components of the action (i.e., high performance and high attention control) and functionally optimal but unpleasant emotional states (i.e., high performance and unpleasant hedonic valence). This state is likely to occur in a condition appraised as challenging, engendering concurrent distractions, and interfering with dominant action tendencies, for example, while executing demanding tasks or strenuous physical activities, dealing with novel problems or unexpected events, or under competitive stress. In this case, some reinvestment of attention in the skill is not only unavoidable (Masters \& Maxwell, 2008) but even beneficial, provided that the focus of attention is on previously identified core components of the action (Hanin \& Hanina, 2009; Hanin et al., 2016). In the MAP perspective (Bortoli et al., 2012; Robazza et al., 2016a), core components should not be mistaken with what athletes and coaches commonly think to be the most important technical parts of an action. Highly automated techniques, such as stance and balance in shooting sports, can be consistently executed in a variety of conditions without conscious attentional control. Rather, core components are construed as fundamental movements or action-related behaviors (such as "positioning," "grip," or "aiming" in precision sports) subjected to variability and accuracy fluctuations, especially under challenging situations. An appropriate focus on the core components is suggested to prevent excessive reinvestment of attention on the action or distraction from task-relevant cues, and to facilitate the transition to a more autonomous execution (Hanin \& Hanina, 2009).

\section{Similarities With Other Theoretical Approaches}

The notion of two performance states concurs with several theoretical perspectives and empirical evidence. Based on existing theories in general psychology accounting for a 
wide range of phenomena related to reasoning, judgment, and decision-making, proponents of dual-process theories maintain that human behavior is governed by two different modes of processing, namely, automatic and controlled (Furley, Schweizer, \& Bertrams, 2015; Furley \& Wood, 2016). Evans and Stanovich (2013) have strongly emphasized the features of two distinct types of processing in a default-interventionist framework. Type 1 (default) autonomous processing is "intuitive," allows for fast and effortless execution of behavioral responses, does not rely on working memory and controlled attention, and initiates in the presence of relevant triggering conditions but without subsequent awareness. A more reflective Type 2 (interventionist) controlled processing is suitable when facing novel problems, unpredictable events, or new challenges; relies on working memory capacity; and involves intentional behavior with conscious awareness. Skilled performers are able to alternate between different modes of processing to deal with pressure or adapt to the complexity of competitive demands.

This perspective is akin to the Toner, Montero, and Moran (2016) position advocating the Colombetti (2011) taxonomy mode of bodily self-awareness. Toner et al. argued that skilled performers might experience a pre-reflective or reflective bodily awareness, depending on the focus of attention during skill execution. They also proposed that pre-reflective modes of awareness underpin an external focus of attention or "flow" states, while reflective modes characterize "somaesthetic," proprioceptive awareness (i.e., information about body positions and movements coming from receptors in the joints, tendons, ligaments, muscles, and skin). Experts appear to have developed finely tuned patterns of attention, which allow them to shift between pre-reflective and reflective modes of bodily awareness to ensure a correct skill execution. The dynamic interplay of these two forms of awareness enables skilled performers to monitor the efficacy of their performance, enhance their sense of agency, confront the pervasive challenges of competitive environments, achieve optimal outcomes, and enjoy the 
experience (Toner \& Moran, 2014). Swann and colleagues also contended that superior performance could be reached in a flow state or in a clutch state (Swann et al., 2017a; Swann, Crust, \& Vella, 2017b; Swann, Keegan, Crust, \& Piggott, 2016). A "let it happen" attitude underlies flow, described as a state of effortless attention, an absence of critical thoughts, and an automatic/effortless experience, while a "make it happen" attitude typifies a clutch state, conceived as a more effortful condition than flow, with deliberate focus on the task, intense effort, and heightened awareness of the situation and demands. The two states share common features, such as perceived control, absorption, confidence, enhanced motivation, and enjoyment. Notably, it is suggested that athletes can move from one state to the other during the same performance.

In a similar vein, Geeves and colleagues proposed a nuanced model of expert skill, named the applying intelligence to the reflexes (AIR) approach, in an attempt to explain the "to think or not to think" apparent paradox (Geeves, McIlwain, Sutton, \& Christensen, 2014; Sutton, McIlwain, Christensen, \& Geeves, 2011). On stage, expert musicians not only need to accurately retrieve the information encoded over many hours of practice, but also have to face the demands of a constantly evolving situation. According to Geeves et al. (2014), "The AIR model proposes that expert skill in music performance (and in other domains) relies on a mindedness that facilitates the dynamic flexibility of attention, allowing it to be allocated freely and in a way that best meets contingent contextual demands.” (p. 676, italics added). Minded thinking involves a free and flexible allocation of an expert's attention addressing those variables that are most important in a given moment. In the AIR model, equal emphasis is placed on overarching, highly-cognitive (top-down) processes, and mindless (bottom-up) embodied feelings and actions. The model provides an account of how proficient musicians, as well as performers across a wide variety of domains, are able to accurately retrieve information from long-term memory and, at the same time, remain open to meet ever- 
changing demands. Some performers may be inclined to rely more on top-down processes, while others rely on bottom-up processes. Yet, a dynamic interaction between the two mechanisms is expected to give rise to more flexible and adaptive behaviors.

The theoretical approaches mentioned in this section share common ideas and provide empirical evidence supporting the desirability and applicability of some type and degree of conscious motor processing under pressure. Accordingly, Carson and Collins (2016) proposed a motoric perspective highlighting the crucial role of the information-bearing structures involved in movement production. They added a fourth dimension, termed skill establishment, to the three-dimensional model of the anxiety-performance relationship. The three-dimensional model, advanced by Cheng, Hardy, and Markland (2009), includes the cognitive anxiety, physiological anxiety, and perceived control dimensions. Skill establishment comprises the level and consistency of movement automaticity combined with the individual's confidence in this specific process against dysfunctional effects of anxiety. This notion informs an applied perspective on countering anxiety through a positive selffocus. A main conclusion is that thinking per se is not the problem, but rather thought content (what) and type (how). Holistic thoughts summarizing the movement's entirety are suggested to protect from maladaptive cognitions and enhance memory retrieval. For example, temporally-accurate rhythmical cues can act as a useful source of information for movement components' retrieval from motor memory and prompt optimal movement patterns with a lower level of conscious attention (MacPherson, Collins, \& Obhi, 2009). To be effective, holistic thoughts should be multisensory and include proprioceptive cues to prevent total subconscious control, thus giving room to subtle adaptations according to environmental requests (Toner \& Moran, 2015).

In addition to the theoretical perspectives described in this section, the MAP model shares some similarities with the attentional control theory (Eysenck, Derakshan, Santos, \& 
Calvo, 2007). This approach will be outlined below in the MAP and attentional control theory section.

\section{Not Only Optimal Performance}

Beyond Type 1 and Type 2 optimal performance states discussed above and related to other theoretical views, two types of dysfunctional processing are conceptualized in the MAP model (Figure 3, Panel A and Panel B; Bortoli et al., 2012; Robazza et al., 2016a). Type 3 state can be experienced under adverse conditions of stress, exhaustion, or sudden unpredictable issues that often arise under pressure, especially when the performer lacks relevant experience and self-regulatory skills. Threat appraisal stemming from anticipated harm can elicit catastrophic thoughts and related dysfunctional-unpleasant emotions. In the attempt to deal with situational demands, amend technical flaws, and recover from underperformance, the individual can spend much effort in drawing attention to taskirrelevant cues (e.g., negative thoughts, emotional responses, and external distractions) or movement execution. Distraction and an excessive reinvestment of conscious attention to the execution of well-learned skills tend to replace meta-cognitive task-relevant attention and functional goal-directed behavior (Wegner, 1994), disrupt fluidity and automaticity, cause loss of energy, and therefore hamper performance (Beilock \& Gray, 2012; Maxwell, Masters, \& Eves, 2000; Oudejans, Kuijpers, Kooijman, \& Bakker, 2011). Finally, the MAP model also includes a Type 4 dysfunctional processing. This state may occur when task engagement is low, and the individual does not invest enough energy or make adequate effort to accomplish the task. Although the emotional experience may be pleasant, for example after a recent success that engenders complacency, attentional focus is lacking and the ensuing behavior is not controlled enough or supervised appropriately to warrant optimal execution. 
According to the MAP model tenets, the $2 \times 2 \times 2$ interplay among performance, attention control, and hedonic valence levels gives rise to multiple dimensional states (Figure 3, Panel C). Proficient people should be able to consistently reach and maintain optimal performance states by adjusting their degree of conscious attention control and hedonic valence according to their current state and situational demands. Finely tuned patterns of attention and valence allow performers to flexibly alternate between Type 1 and Type 2 states. To facilitate this process, they need to focus on the present moment situation, become aware of their own current psychophysical conditions and mindfully accept them rather than struggle to control them (Gardner \& Moore, 2007). In fact, present moment attention and awareness can help to sustain and direct their attentional focus, and suppress interfering information (Toner et al., 2016). Self-regulation of attentional control and hedonic valence levels can be conducted using a mixture of action-centered strategies (e.g., attending to the core components of the action) and emotion-centered strategies (e.g., somatic and thought regulation). These strategies should help the performer to either alternate between Type 1 and Type 2 processing as needed, or to regain an optimal condition.

Empirical evidence supports the above assumptions. The theoretical basis of the MAP model derived from applied consultancy work with top-level pistol and rifle shooters (Bortoli et al., 2012). Shooters who applied MAP-based self-regulation were able to deal with dysfunctional effects of distress in practice and simulated competitions. In a related study on shooting, Robazza et al. (2016a) examined the individuals' fluctuations of perceived control and hedonic valence dimensions during performance using a probabilistic approach (Kamata et al., 2002). As expected, findings showed within and between individual differences in intensity and probability levels across the four performance categories. Shooters exhibited idiosyncratic zones of optimal functioning (Type 1 and Type 2) and suboptimal functioning (Type 3 and Type 4) on both perceived control and valence intensities. Analysis of the 
temporal pattern showed that fluctuations of these intensity levels during execution were also idiosyncratic and changed over time among the four types of processing. Overall results suggest the use of both action- and emotion-centered self-regulation to achieve optimal states. To reach and maintain high performance levels, athletes need to become aware of their psychophysiological states and how they fluctuate during task execution (Harmison, 2006). When in a dysfunctional, pleasant or unpleasant state, performers should mindfully accept their state and the situation, focus on the present moment, redirect their attention to the core components of the task (i.e., action-centered regulation), and/or use emotion-centered regulation (Robazza et al., 2004). Action- and emotion-centered self-regulations can be used separately or in combination, depending on whether the performer needs to attend to critical movement cues, regulate emotional states, or both. It is reasonable to assume that the two strategies positively interact with each other. Effectively paying attention to the core components of the action can facilitate adaptation, and therefore improve confidence and emotional states. In turn, enhancing confidence and emotional states can help direct attention to functional cues. It should be pointed out that although hedonic valence, control levels, and performance levels can be distinguished categorically (Figure 3), it may be more useful to think of a continuum of self-regulation possibilities ranging from low to high hedonic valence and control levels (i.e., multiple states) that lead to different performance levels.

The effectiveness of Type 1 and Type 2 attentional processing modalities were further confirmed on college students engaged on an endurance cycling task (Bertollo et al., 2015). Additional studies in pistol shooting, dart throwing, and race car driving, investigating the psychophysiological patterns underlying different types of performance states, such as skin conductance level, skin temperature, breathing rate, heart rate responses, and kinematic patterns, have provided evidence supporting different types of information processing (Bertollo et al., 2013; Filho et al., 2015). Electrodermal activity associated with Type 2 and 
Type 3 performance states, for example, was higher compared to Type 1 and Type 4 performance conditions (Bertollo et al., 2013), thus suggesting the existence of different mechanisms of energy production and utilization. There is also evidence of different neural patterns on elite-level shooters associated with the four performance types (Bertollo et al., 2016; Comani et al., 2014; di Fronso et al., 2016). In a study on shooting, Type 1 performance was characterized by lower alpha power in central, contralateral parietal, and occipital areas at shot release, indicating a global decrease in cortical activity (Comani et al., 2014). On the other hand, Type 2 performance was typified by increased alpha power activity in frontal and occipital areas.

\section{MAP and Attentional Control Theory}

Framed within the MAP model and the attentional control theory (ACT; Eysenck et al., 2007; Eysenck \& Wilson, 2016), a study on theta and alpha frequency bands in shooting showed event related synchronization activity mainly associated with Type 1 performance, and desynchronization activity more related to Type 2 performance (Bertollo et al., 2016). ACT makes a distinction between performance effectiveness (i.e., quality of performance) and processing efficiency (i.e., resources spent in the achievement process). Anxiety is assumed to impair processing efficiency more than performance effectiveness through taskirrelevant thoughts, such as worries or performance concerns, because individuals often try to compensate for the detrimental effects of anxiety by using additional processing resources or exerting more effort. ACT also assumes that there are two attentional systems involving (a) a goal-directed, top-down control of attention through the prefrontal cortex, and (b) a stimulusdriven, bottom-up control of attention through sensory mechanisms. Anxiety would reduce the influence of the top-down system and augment that of the stimulus-driven system, thereby increasing distractibility and attention to threat-related stimuli. However, when leading to the use of compensatory strategies involving processing resources and enhanced effort, anxiety 
may not impair performance effectiveness. The MAP model conceptualization fits well with this view in that processing efficiency typifies Type 1 (fluent) performance (bottom-up control), while performance effectiveness features Type 2 (effortful) performance (top-down control). It is important to note that attentional control theorists (e.g., Eysenck \& Wilson, 2016; Wilson, 2012) acknowledge that competitive pressure can impair both performance efficiency and performance effectiveness. This is the case of Type 3 processing when performers exert too much effort and engage in counterproductive skill focus in the attempt to control the movement mechanics during motor output.

\section{Conclusions}

In this article, the focus was on three theoretical models to provide sound and comprehensive frameworks regarding emotional self-regulation. The process model of emotion regulation (Gross, 1998) was developed in mainstream psychology and then applied in sport (see Terry \& Lane, 2011; Uphill et al., 2009). The IZOF (Hanin, 2000, 2007) and the MAP (Bortoli et al., 2012; Robazza et al., 2016a) models are sport-specific approaches advocating emotion-centered (both models) and action-centered strategies (the MAP) toward the optimization of emotional states and athletic performance. A number of additional perspectives have been mentioned throughout the article in relation to the three models, including biopsychosocial (Blascovich, 2008; Blascovich \& Tomaka, 1996), challenge and threat (Jones et al., 2009), mindfulness- and acceptance-based (Gardner \& Moore, 2007, 2012), dual-process (Evans \& Stanovich, 2013), pre-reflective and reflective (Toner et al., 2016), flow and clutch (Swann et al., 2017a, 2017b), AIR (Geeves et al., 2014), motoric (Carson \& Collins, 2016), and attentional control (Eysenck et al., 2007) models. Yet, several additional theoretical perspectives can inform the development of self-regulation strategies in sport and performance domains. A few examples of prominent approaches are cognitivemotivational-relational (Lazarus, 2000), reversal (Apter, 2006; Kerr, 2001), and control-value 
(Pekrun, 2006) theories. Global integrative frameworks have also been proposed to link appraisals, emotions, cognitions, and behaviors (e.g., Tenenbaum, Basevitch, Gershgoren, \& Filho, 2013; Tenenbaum et al., 2009; see Laborde, 2016, for a discussion).

It is also worth noting that, in a broader perspective, emotional regulation is viewed as closely intertwined with self-regulation processes by which individuals change or adjust their thoughts, feelings, and behaviors to attain goals (Vohs \& Baumeister, 2016). This process involves setting goals, planning actions and strategies, executing behaviors, monitoring progress, postponing gratification, solving goal conflicts, executing corrective actions, and revising goals. Emotion as a main component of the motivational system can be the reference value that triggers self-regulation and indicates progress toward goal attainment. Given the many theoretical models developed in general psychology and sport psychology, there is a clear need to integrate the different views. This integration would enable researchers and practitioners to attain a better knowledge of the emotion-performance relationship (Laborde, Raab, \& Dosseville, 2013), as well as the emotion regulation and self-regulation of thoughts, feelings, and behaviors in sport, performance, and achievement settings. A multiple states (MuSt) integrative and comprehensive perspective - a MuSt (theory) for sport and performance psychologists — should account for the manifold and nuanced optimal and nonoptimal performance states, and provide a more advanced understanding of emotional regulation and self-regulation processes of performers, particularly when involved in pressurized achievement contexts. 


\section{References}

Aldao, A., Nolen-Hoeksema, S., \& Schweizer, S. (2010). Emotion-regulation strategies across psychopathology: A meta-analytic review. doi:10.1016/j.cpr.2009.11.004. Clinical Psychology Review, 30, 217-237.

Apter, M. J. (2006). Reversal theory: The dynamics of motivation, emotion, and personality (2nd ed.). Oxford, UK: Oneworld Publications.

Bandura, A. (1997). Self-efficacy: The exercise of control. New York, NY: Freeman.

Baumeister, R. F., Vohs, K. D., \& Tice, D. M. (2007). The strength model of self-control. doi:10.1111/j.1467-8721.2007.00534.x. Current Directions in Psychological Science, 16, 351-355.

Beedie, C., Terry, P., \& Lane, A. (2005). Distinctions between emotion and mood. doi:10.1080/02699930541000057. Cognition and Emotion, 19, 847-878.

Beilock, S. L., \& Gray, R. (2012). From attentional control to attentional spillover: A skilllevel investigation of attention, movement, and performance outcomes. doi:10.1016/j.humov.2012.02.014. Human Movement Science, 31, 1473-1499.

Bertollo, M., Bortoli, L., Gramaccioni, G., Hanin, Y., Comani, S., \& Robazza, C. (2013). Behavioural and psychophysiological correlates of athletic performance: A test of the multi-action plan model. doi:10.1007/s 10484-013-9211-z. Applied Psychophysiology and Biofeedback, 38, 91-99.

Bertollo, M., di Fronso, S., Filho, E., Conforto, S., Schmid, M., Bortoli, L., . . Robazza, C. (2016). Proficient brain for optimal performance: The MAP model perspective. doi:10.7717/peerj.2082. PeerJ, 4, e2082.

Bertollo, M., di Fronso, S., Filho, E., Lamberti, V., Ripari, P., Reis, M. V., . . Robazza, C. (2015). To focus or not to focus: Is attention on the core components of action beneficial for cycling performance?. doi:10.1123/tsp.2014-0046 The Sport Psychologist, 29, 110119.

Blascovich, J. (2008). Challenge and threat. In A. J. Elliot (Ed.), Handbook of approach and avoidance motivation (pp. 431-445). New York, NY: Psychology Press.

Blascovich, J., \& Tomaka, J. (1996). The biopsychosocial model of arousal regulation. doi:10.1016/S0065-2601(08)60235-X. Advances in Experimental Social Psychology, 28, $1-51$.

Bortoli, L., Bertollo, M., Hanin, Y., \& Robazza, C. (2012). Striving for excellence: A multiaction plan intervention model for shooters. doi:10.1016/j.psychsport.2012.04.006. Psychology of Sport and Exercise, 13, 693-701.

Brown, D. J., \& Fletcher, D. (2017). Effects of psychological and psychosocial interventions on sport performance: A meta-analysis. doi:10.1007/s40279-016-0552-7. Sports Medicine, 47, 77-99.

Bushman, B. J. (2002). Does venting anger feed or extinguish the flame? Catharsis, rumination, distraction, anger, and aggressive responding. doi:10.1177/0146167202289002. Personality and Social Psychology Bulletin, 28, 724 731.

Campos, J. J., Walle, E. A., Dahl, A., \& Main, A. (2011). Reconceptualizing emotion regulation. doi:10.1177/1754073910380975. Emotion Review, 3, 26-35.

Carson, H. J., \& Collins, D. (2016). Implementing the Five-A Model of technical refinement: Key roles of the sport psychologist. doi:10.1080/10413200.2016.1162224. Journal of Applied Sport Psychology, 28, 392-409.

Cheng, W.-N. K., Hardy, L., \& Markland, D. (2009). Toward a three-dimensional conceptualization of performance anxiety: Rationale and initial measurement development. doi:10.1016/j.psychsport.2008.08.001. Psychology of Sport and Exercise, 10, 271-278. 
Clore, G., \& Huntsinger, J. R. (2007). How emotions inform judgment and regulate thought. doi:10.1016/j.tics.2007.08.005. Trends in Cognitive Science, 11, 393-399.

Colombetti, G. (2011). Varieties of pre-reflective self-awareness: Foreground and background bodily feelings in emotion experience. doi:10.1080/0020174X.2011.575003. Inquiry, 54, 293-313.

Comani, S., Bortoli, L., Di Fronso, S., Filho, E., De Marchis, C., Schmid, M., . . B Bertollo, M. (2014). ERD/ERS patterns of shooting performance within the multi-action plan model. doi:10.1007/978-3-319-00846-2_35. In L. M. R. Romero (Ed.), XIII Mediterranean Conference on Medical and Biological Engineering and Computing (Vol. 41, pp. 141144). Seville, Spain: Springer.

Cotterill, S. (2010). Pre-performance routines in sport: Current understanding and future directions. doi:10.1080/1750984x.2010.488269. International Review of Sport and Exercise Psychology, 3, 132-153.

Csikszentmihalyi, M., Latter, P., \& Duranso, C. W. (2017). Running flow. Champaign, IL: Human Kinetics.

di Fronso, S., Robazza, C., Filho, E., Bortoli, L., Comani, S., \& Bertollo, M. (2016). Neural markers of performance states in an Olympic athlete: An EEG case study in air-pistol shooting. Journal of Sports Science and Medicine, 15, 214-222.

Edmonds, W. A., Tenenbaum, G., Mann, D. T. Y., Johnson, M., \& Kamata, A. (2008). The effect of biofeedback training on affective regulation and simulated car-racing performance: A multiple case study analysis. doi:10.1080/02640410701813068. Journal of Sports Sciences, 26, 761-773.

Ekkekakis, P. (2012). The measurement of affect, mood, and emotion in exercise psychology. In G. Tenenbaum, R. C. Eklund, \& A. Kamata (Eds.), Measurement in sport and exercise psychology (pp. 321-332). Champaign, IL: Human Kinetics.

Elliot, A. J., Eder, A. B., \& Harmon-Jones, E. (2013). Approach-avoidance motivation and emotion: Convergence and divergence. doi:10.1177/1754073913477517. Emotion Review, 5, 308-311.

Ericsson, K. A. (2003). Development of elite performance and deliberate practice: An update from the perspective of the expert performance approach. In J. L. Starkes, \& K. A. Ericsson (Eds.), Expert performance in sports: Advances in research on sport expertise (pp. 49-83). Champaign, IL: Human Kinetics.

Evans, J. St. B. T., \& Stanovich, K. E. (2013). Dual-process theories of higher cognition: Advancing the debate. doi:10.1177/1745691612460685. Perspectives on Psychological Science, 8, 223-241.

Eysenck, M. W., Derakshan, N., Santos, R., \& Calvo, M. G. (2007). Anxiety and cognitive performance: Attentional control theory. doi:10.1037/1528-3542.7.2.336. Emotion, 7, 336353.

Eysenck, M. W., \& Wilson, M. R. (2016). Sporting performance, pressure and cognitionIntroducing attentional control theory: Sport. In D. Groome \& M. W. Eysenck (Eds.), An introduction to applied cognitive psychology (2nd ed., pp. 329-350). New York, NY: Routledge.

Farb, N. A. S., Anderson, A. K., Irving, J. A., \& Segal, Z. V. (2014). Mindfulness interventions and emotion regulation. In J. J. Gross (Ed.), Handbook of emotion regulation (2nd ed., pp. 548-567). New York, NY: The Guilford Press.

Feltz, D. L., Short, S. E., \& Sullivan, P. J. (2008). Self-efficacy in sport: Research and strategies for working with athletes, teams, and coaches. Champaign, IL: Human Kinetics.

Filho, E., di Fronso, S., Mazzoni, C., Robazza, C., Bortoli, L., \& Bertollo, M. (2015). My heart is racing! Psychophysiological dynamics of skilled racecar drivers. doi:10.1080/02640414.2014.977940. Journal of Sports Sciences, 33, 945-959. 
Friesen, A. P., Lane, A. M., Devonport, T. J., Sellars, C. N., Stanley, D. N., \& Beedie, C. J. (2013). Emotion in sport: Considering interpersonal regulation strategies. doi:10.1080/1750984x.2012.742921. International Review of Sport and Exercise Psychology, 6, 139-154.

Furley, P., Schweizer, G., \& Bertrams, A. (2015). The two modes of an athlete: Dual-process theories in the field of sport. doi:10.1080/1750984X.2015.1022203. International Review of Sport and Exercise Psychology, 8, 106-124.

Furley, P., \& Wood, G. (2016). Working memory, attentional control, and expertise in sports: A review of current literature and directions for future research.

doi:10.1016/j.jarmac.2016.05.001. Journal of Applied Research in Memory and Cognition, $5,415-425$.

Gardner, F. (2016). Scientific advancements of mindfulness- and acceptance-based models in sport psychology: A decade in time, a seismic shift in philosophy and practice. doi:10.1017/CBO9781139871310.008. In A. Baltzell (Ed.), Mindfulness and performance (pp. 127-152). New York, NY: Cambridge University Press.

Gardner, F. L., \& Moore, Z. E. (2007). The psychology of enhancing human performance: The Mindfulness-Acceptance-Commitment (MAC) approach. New York, NY: Springer.

Gardner, F. L., \& Moore, Z. E. (2012). Mindfulness and acceptance models in sport psychology: A decade of basic and applied scientific advancements. doi:10.1037/a0030220. Canadian Psychology, 53, 309-318.

Geeves, A., McIlwain, D. J. F., Sutton, J., \& Christensen, W. (2014). To think or not to think: The apparent paradox of expert skill in music performance. doi:10.1080/00131857.2013.779214. Educational Philosophy and Theory, 46, 674-691.

Gross, J. J. (1998). The emerging field of emotion regulation: An integrative review. Review of General Psychology, 2, 271-299. doi: 10.1037/1089-2680.2.3.271

Gross, J. J. (2014). Emotion regulation: Conceptual and empirical foundations. In J. J. Gross (Ed.), Handbook of emotion regulation (2nd ed., pp. 3-20). New York, NY: The Guilford Press.

Gross, J. J. (2015). Emotion regulation: Current status and future prospects. doi:10.1080/1047840X.2014.940781. Psychological Inquiry, 26, 1-26.

Gross, J. J., Sheppes, G., \& Urry, H. L. (2011). Emotion generation and emotion regulation: A distinction we should make (carefully) . doi:10.1080/02699931.2011.555753. Cognition and Emotion, 25, 765-781.

Hanin, Y. L. (2000). Individual zones of optimal functioning (IZOF) model: Emotionperformance relationships in sport. In Y. L. Hanin (Ed.), Emotions in sport (pp. 65-89). Champaign, IL: Human Kinetics.

Hanin, Y. L. (2007). Emotions in sport: Current issues and perspectives. In G. Tenenbaum \& R. C. Eklund (Eds.), Handbook of sport psychology (3rd ed., pp. 31-58). Hoboken, NJ: John Wiley \& Sons.

Hanin, Y. L. (2010). Coping with anxiety in sport. In A. R. Nicholls (Ed.), Coping in sport: Theory, methods, and related constructs (pp. 159-175). Hauppauge, NY: Nova Science.

Hanin, Y., \& Hanina, M. (2009). Optimization of performance in top-level athletes: An action-focused coping approach. International Journal of Sports Science and Coaching, 4, 47-58. doi: 10.1260/1747-9541.4.1.47

Hanin, Y., Hanina, M., Šašek, H., \& Kobilšek, A. (2016). Emotion-centered and actioncentered coping in elite sport: Task execution design approach. International Journal of Sports Science and Coaching, 11, 566-588. doi: 10.1177/1747954116654782

Harmison, R. J. (2006). Peak performance in sport: Identifying ideal performance states and developing athletes' psychological skills. Professional Psychology. doi:10.1037/07357028.37.3.233. Research and Practice, 37, 233-243. 
Harmison, R. J., \& Casto, K. V. (2012). Optimal performance: Elite level performance in “The Zone. doi:10.1093/oxfordhb/9780199731763.013.0038." In S. M. Murphy (Ed.), The Oxford handbook of sport and performance psychology (pp. 707-724). New York, NY: Oxford University Press.

Hays, K. (2017). Performance psychology with performing artists psychology.oxfordre.com/view/10.1093/acrefore/9780190236557.001.0001/acrefore9780190236557-e-191. In Oxford research encyclopedia of psychology.

Jones, M., Meijen, C., McCarthy, P. J., \& Sheffield, D. (2009). A theory of challenge and threat states in athletes. doi:10.1080/17509840902829331. International Review of Sport and Exercise Psychology, 2, 161-180.

Jones, M. V. (2012). Emotion regulation and performance. In S. Murphy (Ed.), The Oxford handbook of sport and performance psychology (pp. 154-172). New York, NY: Oxford University Press.

Kabat-Zinn, J. (1990). Full catastrophe living: Using the wisdom of your body and mind to face stress, pain and illness. New York, NY: Delacorte.

Kamata, A., Tenenbaum, G., \& Hanin, Y. L. (2002). Individual zone of optimal functioning (IZOF): A probabilistic estimation. Journal of Sport and Exercise Psychology, 24, 189208. doi: 10.1123/jsep.24.2.189

Karageorghis, C. I. (2017). Applying music in exercise and sport. Champaign, IL: Human Kinetics.

Kerr, J. (2001). Counselling athletes: Applying reversal theory. New York, NY: Routledge.

Laborde, S. (2016). Bridging the gap between emotion and cognition: An overview. In M. Raab, B. Lobinger, S. Hoffmann, A. Pizzera, \& S. Laborde (Eds.), Performance psychology: Perception, action, cognition, and emotion (pp. 275-289). London, UK: Elsevier.

Laborde, S., Raab, M., \& Dosseville, F. (2013). Emotions and performance: Valuable insights from the sports domain. In C. Mohiyeddini, M. Eysenck, \& S. Bauer (Eds.), Handbook of psychology of emotions: Recent theoretical perspectives and novel empirical findings (pp. 325-358). New York, NY: Nova Science.

Lane, A. M., Beedie, C. J., Jones, M. V., Uphill, M., \& Devonport, T. J. (2012). The BASES expert statement on emotion regulation in sport. doi:10.1080/02640414.2012.693621. Journal of Sports Sciences, 30, 1189-1195.

Lazarus, R. S. (2000). How emotions influence performance in competitive sports. doi:10.1123/tsp.14.3.229. The Sport Psychologist, 14, 229-252.

Lazarus, R. S., \& Folkman, S. (1984). Stress, appraisal, and coping. New York, NY: Springer-Verlag.

MacPherson, A. C., Collins, D., \& Obhi, S. S. (2009). The importance of temporal structure and rhythm for the optimum performance of motor skills: A new focus for practitioners of sport psychology. Journal of Applied Sport Psychology, 21, S48-S61. doi: $10.1080 / 10413200802595930$

Masters, R., \& Maxwell, J. (2008). The theory of reinvestment. doi:10.1080/17509840802287218. International Review of Sport and Exercise Psychology, $1,160-183$.

Maxwell, J. P. (2004). Anger rumination: An antecedent of athlete aggression?. doi:10.1016/S1469-0292(03)00007-4 Psychology of Sport and Exercise, 5, 279-289.

Maxwell, J. P., Masters, R. S. W., \& Eves, F. F. (2000). From novice to no know-how: A longitudinal study of implicit motor learning. Journal of Sports Sciences, 18, 111-120. doi: 10.1080/026404100365180

McGrath, J. S., Moore, L. J., Wilson, M. R., Freeman, P., \& Vine, S. J. (2011). Challenge and threat states in surgery: Implications for surgical performance and training. 
doi:10.1111/j.1464-410X.2011.10558.x. British Journal of Urology International, 108, 795-796.

Mesagno, C., Hill, D. M., \& Larkin, P. (2015). Examining the accuracy and in-game performance effects between pre- and post-performance routines: A mixed methods study. doi:10.1016/j.psychsport.2015.03.005. Psychology of Sport and Exercise, 19, 85-94.

Middleton, T., Ruiz, M. C., \& Robazza, C. (2017). Regulating pre-performance psychobiosocial states with music. The Sport Psychologist, 31, 227-236. doi: 10.1123/tsp.2016-0081

Moore, Z. (2016). Mindfulness, emotion regulation, and performance. doi:10.1017/CBO9781139871310.003. In A. Baltzell (Ed.), Mindfulness and performance (pp. 29-52). New York, NY: Cambridge University Press.

Munroe-Chandler, K., \& Guerrero, M. (2017). Psychological imagery in sport and performance psychology.oxfordre.com/view/10.1093/acrefore/9780190236557.001.0001/acrefore9780190236557-e-228. In Oxford research encyclopedia of psychology.

Muraven, M., \& Baumeister, R. F. (2000). Self-regulation and depletion of limited resources: Does self-control resemble a muscle?. doi:10.1037/0033-2909.126.2.247 Psychological Bulletin, 126, 247-259.

Nieuwenhuys, A., Vos, L., Pijpstra, S., \& Bakker, F. (2011). Meta experiences and coping effectiveness in sport. Psychology of Sport and Exercise, 12, 135-143. doi: 10.1016/j.psychsport.2010.07.008

Niven, K., Totterdell, P., Stride, C. B., \& Holman, D. (2011). Emotion regulation of others and self (EROS): The development and validation of a new individual difference measure. doi:10.1007/s12144-011-9099-9. Current Psychology, 30, 53-73.

Oudejans, R. R. D., Kuijpers, W., Kooijman, C. C., \& Bakker, F. C. (2011). Thoughts and attention of athletes under pressure: Skill-focus or performance worries? . doi:10.1080/10615806.2010.481331 Anxiety, Stress, and Coping, 24, 59-73.

Pekrun, R. (2006). The control-value theory of achievement emotions: Assumptions, corollaries, and implications for educational research and practice. doi:10.1007/s10648006-9029-9. Educational Psychology Review, 18, 315-341.

Peña-Sarrionandia, A., Mikolajczak, M., \& Gross, J. J. (2015). Integrating emotion regulation and emotional intelligence traditions: A meta-analysis. doi:10.3389/fpsyg.2015.00160. Frontiers in Psychology, 6(160).

Quoidbach, J., Mikolajczak, M., \& Gross, J. J. (2015). Positive interventions: An emotion regulation perspective. doi:10.1037/a0038648. Psychological Bulletin, 141, 655-693.

Ray, R. D., McRae, K., Ochsner, K. N., \& Gross, J. J. (2010). Cognitive reappraisal of negative affect: Converging evidence from EMG and self-report. doi:10.1037/a001901533. Emotion, 10, 587-592.

Richards, J. M., \& Gross, J. J. (2000). Emotion regulation and memory: The cognitive costs of keeping one's cool[10.1037/0022-3514.79.3.410. Journal of Personality and Social Psychology, 79, 410-424.

Rimé, B. (2009). Emotion elicits the social sharing of emotion: Theory and empirical review. doi:10.1177/1754073908097189. Emotion Review, 1, 60-85.

Robazza, C., Bertollo, M., Filho, E., Hanin, Y., \& Bortoli, L. (2016a). Perceived control and hedonic tone dynamics during performance in elite shooters. doi:10.1080/02701367.2016.1185081. Research Quarterly for Exercise and Sport, 87, 284294.Robazza, C., Bertollo, M., Ruiz, M. C., \& Bortoli, L. (2016b). Measuring psychobiosocial states in sport: Initial validation of a trait measure. doi:10.1371/journal.pone.0167448. PLoS ONE, 11(12), e0167448. 
Robazza, C., \& Bortoli, L. (2007). Perceived impact of anger and anxiety on sporting performance in rugby players. doi:10.1016/j.psychsport.2006.07.005. Psychology of Sport and Exercise, 8, 875-896.

Robazza, C., Pellizzari, M., \& Hanin, Y. (2004). Emotion self-regulation and athletic performance: An application of the IZOF model. doi:10.1016/S1469-0292(03)00034-7. Psychology of Sport and Exercise, 5, 379-404.

Ruiz, M. C., Hanin, Y. L., \& Robazza, C. (2016). Assessment of performance-related experiences: An individualized approach. doi:10.1123/tsp.2015-0035. The Sport Psychologist, 30, 201-218.

Ruiz, M. C., Raglin, J. S., \& Hanin, Y. L. (2017). Individual zones of optimal functioning (IZOF) model (1878-2014): Historical overview of its development and use. doi:10.1080/1612197X.2015.1041545. International Journal of Sport and Exercise Psychology, 15, 41-63.

Ruiz, M. C., Robazza, C., Tolvanen, A., \& Hanin, Y. L. (2018). The psychobiosocial states scale (PBS-S): Factor structure and reliability. doi:10.1027/1015-5759/a000454. European Journal of Psychological Assessment. Advance online publication.

Russell, J. A. (2003). Core affect and the psychological construction of emotion. doi:10.1037/0033-295X.110.1.145. Psychological Review, 110, 145-172.

Sappington, R., \& Longshore, K. (2015). Systematically reviewing the efficacy of mindfulness-based interventions for enhanced athletic performance. doi:10.1123/jcsp.2014-0017. Journal of Clinical Sport Psychology, 9, 232-262.

Scarantino, A. (2015). Basic emotions, psychological construction, and the problem of variability. In L. F. Barrett \& J. A. Russell (Eds.), The psychological construction of emotion (pp. 334-376). New York, NY: Guilford Press.

Scorniaenchi, J. A., \& Feltz, D. L. (2010). Coping self-efficacy in sport. In A. R. Nicholls (Ed.), Coping in sport: Theory, methods, and related constructs (pp. 279-292). New York, NY: Nova Science Publishers.

Sheppes, G., \& Meiran, N. (2008). Divergent cognitive costs for online forms of reappraisal and distraction. doi:10.1037/a0013711. Emotion, 8, 870-874.

Shuman, V., \& Scherer, K. R. (2015). Emotions, psychological structure of. In J. D. Wright (Ed.), International encyclopedia of the social \& behavioral sciences (2nd ed., Vol. 7, pp. 526-533). Oxford, UK: Elsevier.

Skinner, E. A., \& Zimmer-Gembeck, M. J. (2007). The development of coping. doi:10.1146/annurev.psych.58.110405.085705. Annual Review of Psychology, 58, 119144.

Sutton, J., McIlwain, D., Christensen, W., \& Geeves, A. (2011). Applying intelligence to the reflexes: Embodied skills and habits between Dreyfus and Descartes.

doi:10.1080/00071773.2011.11006732. Journal of the British Society for Phenomenology, 42, 78-103.

Swann, C., Crust, L., Jackman, P., Vella, S. A., Allen, M. S., \& Keegan, R. (2017a). Psychological states underlying excellent performance in sport: Toward an integrated model of flow and clutch states. doi:10.1080/10413200.2016.1272650. Journal of Applied Sport Psychology, 29, 375-401.

Swann, C., Crust, L., \& Vella, S. A. (2017b). New directions in the psychology of optimal performance in sport: Flow and clutch states. doi:10.1016/j.copsyc.2017.03.032. Current Opinion in Psychology, 16, 48-53.

Swann, C., Keegan, R., Crust, L., \& Piggott, D. (2016). Psychological states underlying excellent performance in professional golfers: "Letting it happen" vs. "making it happen. doi:10.1016/j.psychsport.2015.10.008." Psychology of Sport and Exercise, 23, 101-113. 
Tamir, M. (2009). What do people want to feel and why?: Pleasure and utility in emotion regulation. doi:10.1111/j.1467-8721.2009.01617.x. Current Directions in Psychological Science, 18, 101-105.

Tamir, M., Mitchell, C., \& Gross, J. J. (2008). Hedonic and instrumental motives in anger regulation. doi:10.1111/j.1467-9280.2008.02088.x. Psychological Science, 19, 324-328.

Tamminen, K. A., \& Bennett, E. V. (2017). No emotion is an island: An overview of theoretical perspectives and narrative research on emotions in sport and physical activity. doi:10.1080/2159676X.2016.1254109. Qualitative Research in Sport, Exercise and Health, 9, 183-199.

Tenenbaum, G., Basevitch, I., Gershgoren, L., \& Filho, E. (2013). Emotions-decision-making in sport: Theoretical conceptualization and experimental evidence. doi:10.1080/1612197X.2013.773687. International Journal of Sport and Exercise Psychology, 11, 151-168.

Tenenbaum, G., Hatfield, B. D., Eklund, R. C., Land, W. M., Calmeiro, L., Razon, S., \& Schack, T. (2009). A conceptual framework for studying emotions-cognitions-performance linkage under conditions that vary in perceived pressure. In M. Raab, J. G. Johnson, \& H. R. Heekeren (Eds.), Progress in brain research (Vol. 174), Mind and motion: The bidirectional link between thought and action (pp. 159-178). Amsterdam, The Netherlands: Elsevier.

Terry, P. C., \& Lane, A. M. (2011). Moods and emotions. In T. Morris \& P. C. Terry (Eds.), The new sport and exercise psychology companion (pp. 63-87). Morgantown, WV: Fitness Information Technology.

Toner, J., Montero, B. G., \& Moran, A. (2016). Reflective and prereflective bodily awareness in skilled action. doi:10.1037/cns0000090. Psychology of Consciousness: Theory, Research, and Practice, 3, 303-315.

Toner, J., \& Moran, A. (2014). In praise of conscious awareness: A new framework for the investigation of "continuous improvement" in expert athletes. doi:10.3389/fpsyg.2014.00769. Frontiers in Psychology, 5(769).

Toner, J., \& Moran, A. (2015). Enhancing performance proficiency at the expert level: Considering the role of "somaesthetic awareness. doi:10.1016/j.psychsport.2014.07.006." Psychology of Sport and Exercise, 16, 110-117.

Uphill, M. A., McCarthy, P. J., \& Jones, M. V. (2009). Getting a grip on emotion regulation in sport: Conceptual foundations and practical applications. In S. Hanton \& S. Mellalieu (Eds.), Advances in applied sport psychology: A review (pp. 162-194). New York, NY: Routledge.

Vallerand, R. J., \& Blanchard, C. (2000). The study of emotions in sport and exercise: Historical, definitional, and conceptual perspectives. In Y. Hanin (Ed.), Emotions in sports (pp. 3-37). Champaign, IL: Human Kinetics.

van der Lei, H., \& Tenenbaum, G. (2012). Performance processes within affect-related performance zones: A multi-modal investigation of golf performance. doi:10.1007/s10484012-9195-0. Applied Psychophysiology and Biofeedback, 37, 229-240.

Van Raalte, J., \& Vincent, A. (2017). Self-talk in sport and performance psychology.oxfordre.com/view/10.1093/acrefore/9780190236557.001.0001/acrefore9780190236557-e-157. In Oxford research encyclopedia of psychology.

Vine, S. J., Freeman, P., Moore, L. J., Chandra-Ramanan, R., \& Wilson, M. R. (2013). Evaluating stress as a challenge is associated with superior attentional control and motor skill performance: Testing the predictions of the biopsychosocial model of challenge and threat. doi:10.1037/a0034106. Journal of Experimental Psychology: Applied, 19, 185-194.

Vohs, K. D., \& Baumeister, R. F. (Eds.). (2016). Handbook of self-regulation: Research, theory, and applications (3rd ed.). New York, NY: The Guilford Press. 
Webb, T. L., Miles, E., \& Sheeran, P. (2012). Dealing with feeling: A meta-analysis of the effectiveness of strategies derived from the process model of emotion regulation. doi:10.1037/a0027600. Psychological Bulletin, 138, 775-808.

Wegner, D. M. (1994). Ironic processes of mental control. doi:10.1037/0033-295X.101.1.34. Psychological Review, 101, 34-52.

Wegner, D. M. (2009). How to think, say, or do precisely the worst thing for any occasion. doi:10.1126/science.1167346. Science, 325, 48-51.

Weinberg, R. S., \& Gould, D. (2015). Foundations of sport and exercise psychology (6th ed.). Champaign, IL: Human Kinetics.

Williams, J. M. (2010). Relaxation and energizing techniques for regulation of arousal. In J. M. Williams (Ed.), Applied sport psychology: Personal growth to peak performance (6th ed., pp. 247-266). New York, NY: McGraw-Hill Companies.

Wilson, M. R. (2012). Anxiety: Attention, the brain, the body and performance. In S. Murphy (Ed.), The Oxford handbook of sport and performance psychology (pp. 173-190). New York, NY: Oxford University Press.

Woodcock, C., Cumming, J., Duda, J. L., \& Sharp, L. A. (2012). Working within an individual zone of optimal functioning (IZOF) framework: Consultant practice and athlete reflections on refining emotion regulation skills. doi:10.1016/j.psychsport.2011.11.011. Psychology of Sport and Exercise, 13, 291-302.

Zakrajsek, R., \& Blanton, J. (2017). Evaluation of psychological interventions in sport and exercise settings psychology.oxfordre.com/view/10.1093/acrefore/9780190236557.001.0001/acrefore9780190236557-e-223. In Oxford research encyclopedia of psychology.

Zimmerman, B. J. (2006). Development and adaptation of expertise: The role of selfregulatory processes and beliefs. In K. A. Ericsson, N. Charness, P. J. Feltovich, \& R. R. Hoffman (Eds.), The Cambridge handbook of expertise and expert performance (pp. 705722). New York, NY: Cambridge University Press. 


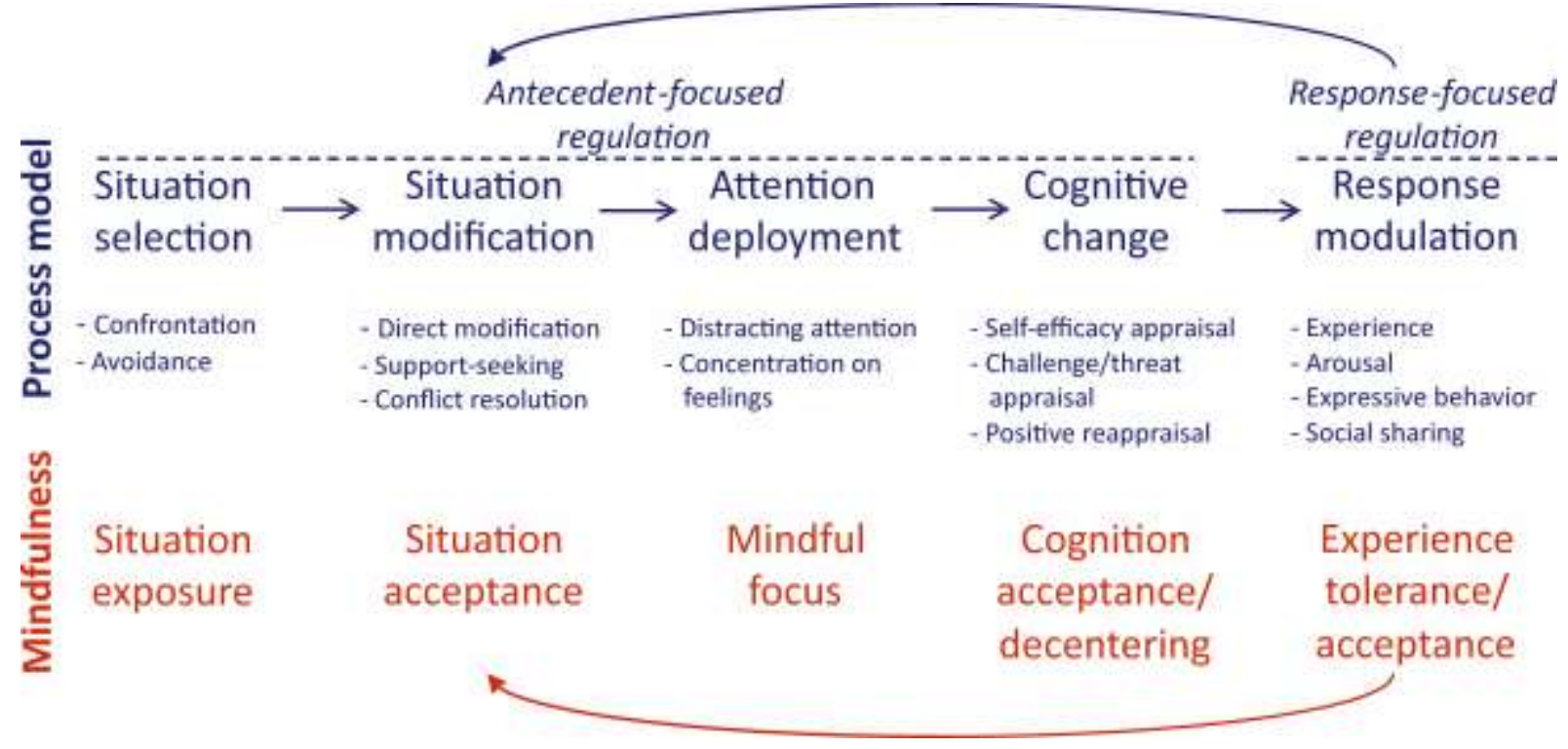

Figure 1. Emotional self-regulation in the framework of the process model (Gross, 1998, 2014), with examples, and mindfulness (Gardner, 2016; Moore, 2016). 


\section{Awareness $\longrightarrow$ Acceptance $\longrightarrow$ Self-regulation}

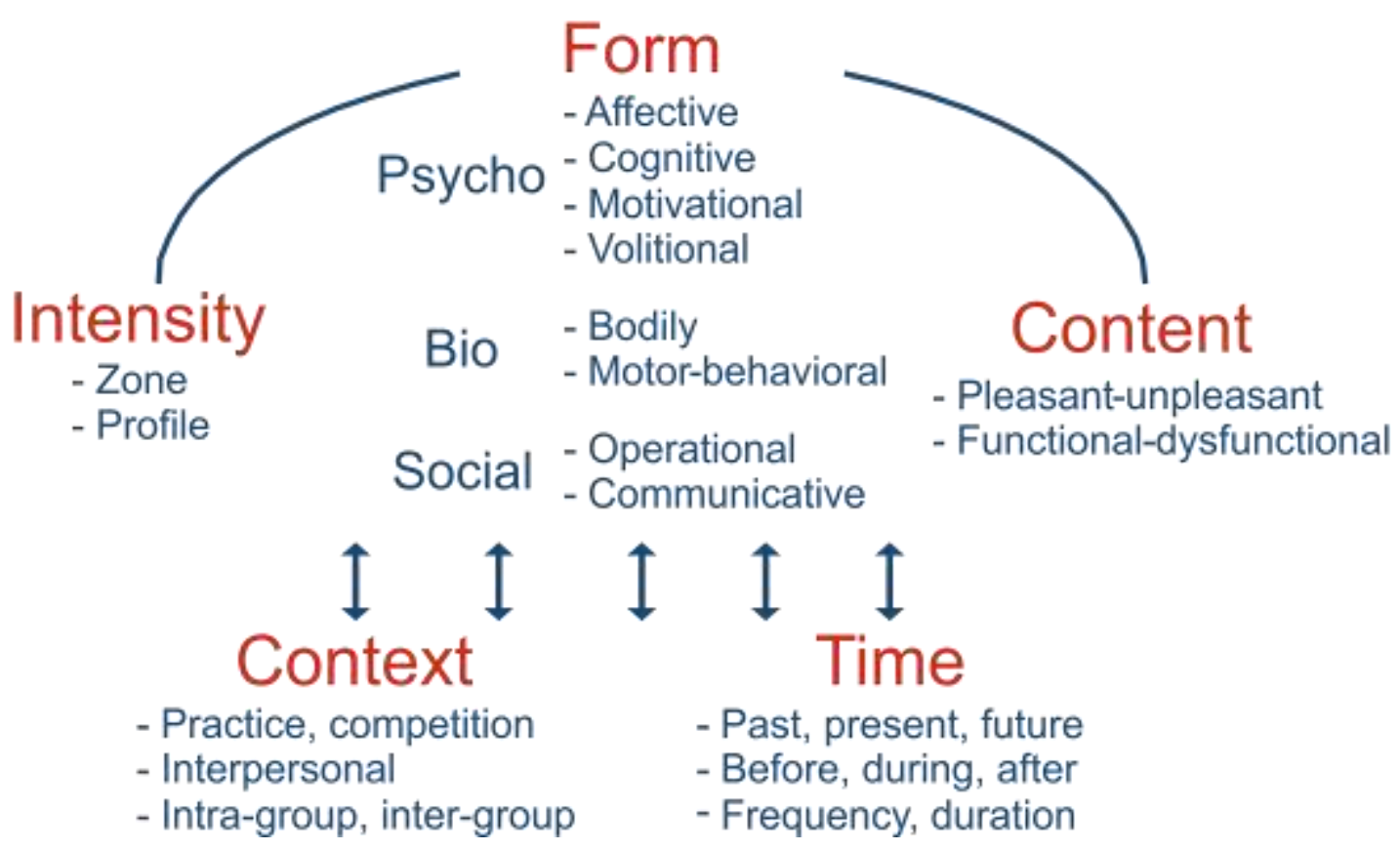

Figure 2. Emotional self-regulation in the framework of the individual zones of optimal functioning (IZOF) model (Hanin, 2007, 2010). Three main characteristics define the structure of state-like experiences (i.e., form, content, and intensity) that occur in a specific context (e.g., practice and competition) and time (e.g., during competition). 

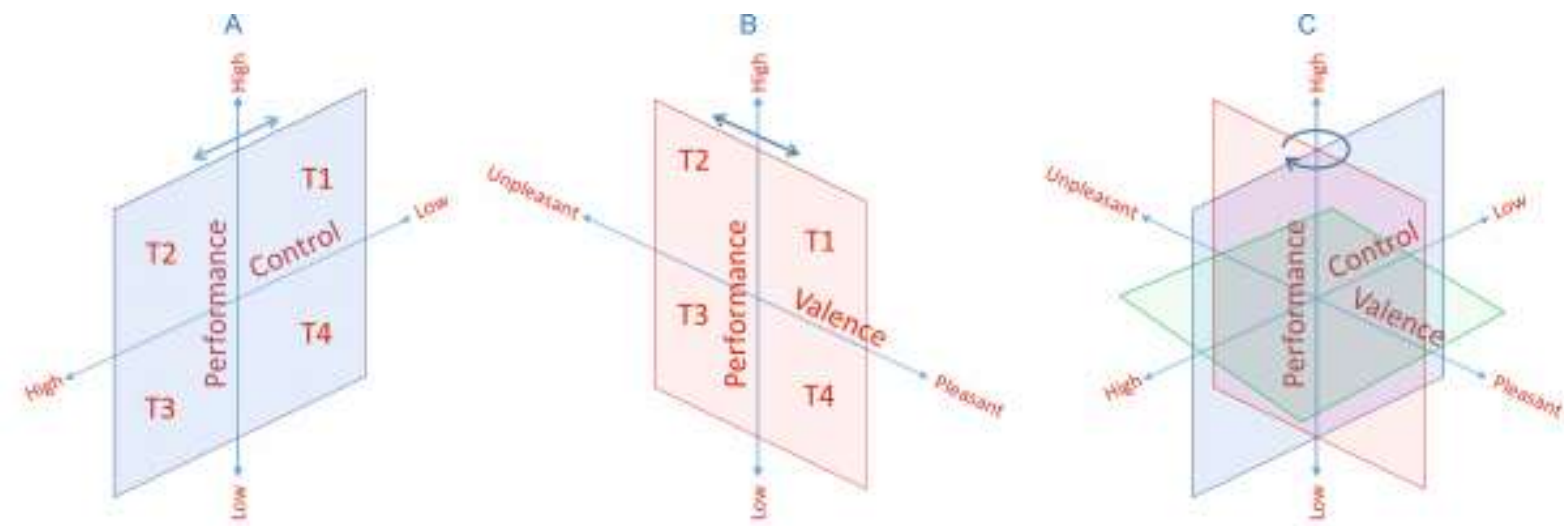

Figure 3. Attention control and hedonic valence levels in relation to performance level as conceived in the multiaction plan model. In Panel A and Panel B, T1, T2, T3, and T4 refer to Type 1, Type 2, Type 3, and Type 4 performance states, respectively, derived from the $2 \times 2$ performance by attention control, and performance by hedonic valence relationships. Panel C portrays the $2 \times 2 \times 2$ interplay among performance, attention control, and hedonic valence. The bidirectional arrows and the circular arrow in the upper part of the panels represent shifts from Type 1 and Type 2 states for high-performance achievements. A combination of action- and emotioncentered self-regulation strategies is expected to facilitate these functional shifts. 